Khalaf : Prediction Of Behaviour Of Reinforced Concrete Deep Beams With Web

\title{
Prediction Of Behaviour Of Reinforced Concrete Deep Beams With Web Openings Using Finite Elements
}

\author{
Khalaf Ibrahem Mohammad, \\ Civil Engineering Department, University Of Mosul
}

\begin{abstract}
This study presents a nonlinear analysis using the finite element method to predict the ultimate load and mode of failure for reinforced concrete deep beams with web openings. Materials nonlinearities due to cracking, plastic flow or crushing of concrete and yield conditions of the reinforcing steel are considered. The capabilities of the proposed model have been examined and demonstrated by analyzing five reinforced concrete deep beams with web openings.
\end{abstract}

Keywords: nonlinear, elasto-perfect plastic, finite element, reinforced concrete, deep beams, web openings.

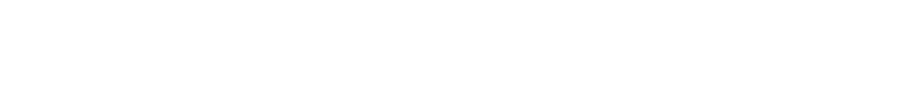

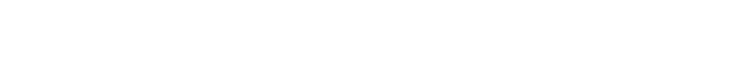

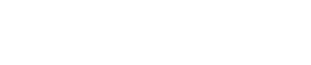

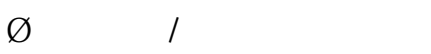 \\ rŮt ŤKE
}

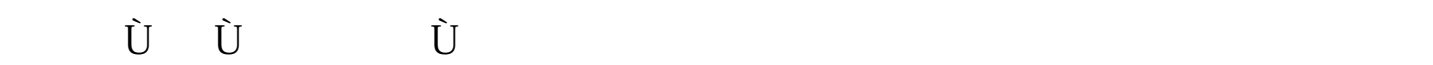

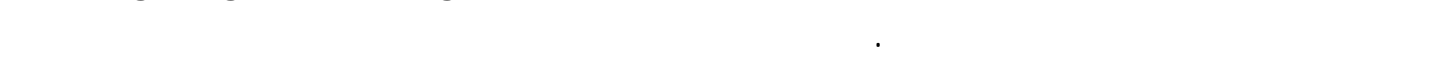

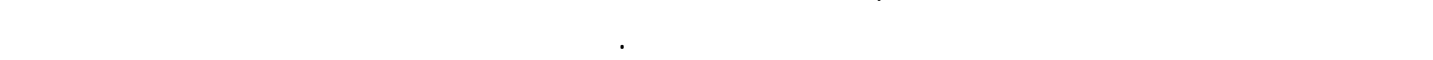

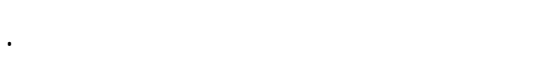




\begin{tabular}{llll} 
Al-Rafidain Engineering & Vol.15 & No.4 & 2007 \\
\hline
\end{tabular}

\section{Introduction}

The exact analysis of reinforced concrete deep beams with web openings presents formidable problems. Existing methods of predicting ultimate strength involve either elastic theory or semi-empirical equations, neither of which is entirely satisfactory [15]. Elastic methods of analysis have been used to predict the location and magnitude of tensile stresses due to openings in deep beams. Although elastic theory is useful for obtaining an under-standing of the way in which the beams carry load, it does not predict the collapse load. Once the first crack has appeared in the beam, the assumption of a homogeneous elastic beam is no longer valid. Some recommendations have been made following experimental investigations of the subjects; of particular note is the truss analogy which led to the development of a semi-empirical design equations for ultimate strength. These equations are found complicated, approximate and a more rigorous solution to the problem is desirable and cannot be used to predict the failure modes of deep beams [6, 7]. It is recognized that finite element methods can provide realistic and satisfactory solutions for nonlinear behaviour of reinforced concrete structures. It is hoped that the finite element analysis proposed in the present study is a step in the right direction.

\section{Finite Element Idealization}

The aim of this study is to develop a simple finite element model which leads to a satisfactory prediction of the behavior of reinforced concrete deep beams with web opening under monotonic loading action. Therefore, two different finite element idealizations are required; idealization for concrete and idealization for reinforcement.

\section{Concrete Idealization}

Concrete is idealized by 2-D plane stress elements. A variety of finite elements are presently available for use in the plane stress analysis. Isoparametric elements have enjoyed considerable appeal because of their simplicity and versatility. Among them, and may be the most widely used, is the eight-noded quadrilateral element. This element has been adopted in this work for concrete idealization. The complete formulation for this element can be found in finite element text [8].

\section{Reinforcement Idealization}

Reinforcement is represented by two-noded axial element embedded any where within a concrete element along local coordinates lines. Perfect bond between the concrete and steel is existed.

Because full compatibility between the bar and basic concrete element is assured, the line of the bar is defined by using the same functions as the basic element [9]. 
Khalaf : Prediction Of Behaviour Of Reinforced Concrete Deep Beams With Web

\section{Materials Modelling Concrete}

\section{Concrete behaviour in compression}

A perfect plasticity approach is used to model the compressive behavior of the concrete. A dual criterion for yielding and crushing in terms of stresses and strains is considered, which is complemented by a tension cut-off representation. The yield condition is formulated in terms of the first two stress invariants $I_{l}$ and $J_{2}$ as [11]

$f\left(I_{I+} J_{2}\right)=\left[\square\left(3 J_{2}\right)+\alpha I_{1}\right]^{1 / 2}=\sigma_{0}$

where $\square$ and $\square$ are material parameters and $\sigma_{0}$ is the effective stress obtained from a uniaxial compression test. Relating this expression to Kupfer et al [10] results, the material parameters are obtained as

$$
\alpha \text { \. } 0.355 \sigma_{0} \text { and } \square \tilde{\varphi} \tilde{1} \square \square \square
$$

and the final expression of the yield criterion can be written in terms of stress components, thus

$$
\begin{gathered}
f(\sigma)=\left\{1.355\left[\left(\sigma_{\mathrm{x}}^{2}+\sigma_{\mathrm{y}}^{2}+\sigma_{\mathrm{z}}^{2}\right)-\left(\sigma_{\mathrm{x}} \sigma_{\mathrm{y}}+\sigma_{\mathrm{x}} \sigma_{\mathrm{z}}+\sigma_{\mathrm{y}} \sigma_{\mathrm{z}}\right)+3\left(\tau_{\mathrm{xy}}^{2}+\tau_{\mathrm{xz}}^{2}+\tau_{\mathrm{yz}}^{2}\right)\right]+\right. \\
\left.0.355 \sigma_{0}\left(\sigma_{\mathrm{x}}+\sigma_{\mathrm{y}}+\sigma_{\mathrm{z}}\right)\right\}^{1 / 2}
\end{gathered}
$$

where $\sigma_{z}$ has a null value in plane stress problems.

In the perfectly plastic model $\sigma_{0}$ is taken as the ultimate stress $f^{\prime}{ }_{c}$ obtained from a uniaxial compressive test. An elastic response is assumed up to when the effective stress reaches $f_{c}^{\prime}$ after which a perfectly plastic response follows until the crushing surface is reached. Figure (1) compares the yield criterion with the experimental results of Kupfer in biaxial stress space [11].

\section{The crushing condition}

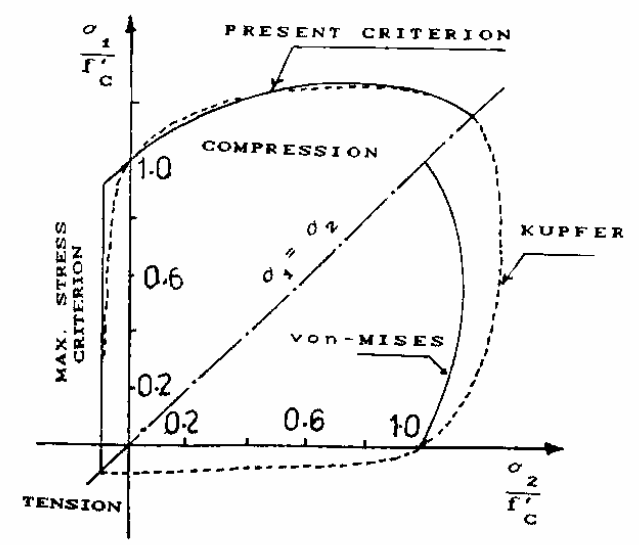

Fig.(1): The yield criterion

The crushing condition is a straincontrolled phenomenon. By a direct conversion of eqn. (1) into strains, the crushing condition can be written as follows: 
$\beta\left(3 J_{2}^{\prime}\right)+\alpha I_{l}^{\prime}=\varepsilon_{c u}^{2}$

where $I_{1}^{\prime}$ and $J_{2}^{\prime}$ are strain invariants and $\varepsilon_{c u}$ is a maximum compressive strain extrapolated from uniaxial test results and is expressed in terms of strain components of plane stress analysis as

$$
1.355\left[\left(\varepsilon_{\mathrm{x}}^{2}+\varepsilon_{\mathrm{y}}^{2}-\varepsilon_{\mathrm{x}} \varepsilon_{\mathrm{y}}\right)+0.75 \gamma_{\mathrm{xy}}^{2}\right]+0.355 \varepsilon_{\mathrm{cu}}\left(\varepsilon_{\mathrm{x}}+\varepsilon_{\mathrm{y}}\right)=\varepsilon_{\mathrm{cu}}^{2}
$$

Crushing or compressive type of fracture is assumed to occur when the effective total strain reaches the maximum compressive strain in a uniaxial compression test. Once crushing has occurred the concrete is assumed to lose all its characteristics of stiffness at the point under consideration.

\section{Concrete behaviour in tension}

The response of concrete under tensile stresses is assumed to be linear elastic until the fracture surface is reached and is governed by a maximum tensile stress criterion. Cracks are assumed to form in planes perpendicular to the direction of maximum principal tensile stress as soon as this reaches the specified concrete tensile strength $f_{t}$. A smeared crack representation is assumed and the cracking strain $\varepsilon_{\text {cr }}$ can be expressed as

$\varepsilon_{\mathrm{cr}}=\frac{f_{t}^{\prime}}{E_{C}}$

where $E_{C}$ is the concrete elastic modulus. Tension stiffening characterizes the postpeak behaviour where the descending part of the stress-strain relationship is modeled by a bilinear decay function (Fig. 2). The parameters $\alpha_{1}$ and $\alpha_{2}$ are the tension stiffening parameters. The choice of specific values for these parameters is very difficult because they have no physical significance. A numerical study by AlManasser and Phillips [12] on the effect of these parameters on the nonlinear solution of reinforced concrete deep beams has shown that best prediction was obtained when setting $\alpha_{1}=10$ and $\alpha_{2}=0.6$.

Due their rough nature, concrete cracks are capable of transmitting shear forces. These forces will induce normal stresses which tend to stiffen the cracked concrete. In the current model the ability of concrete to transfer shear force across the crack interface is accounted for by introducing a reduction factor, $\beta_{\mathrm{s}}$, to the shear modulus of uncracked concrete for cracked concrete. This factor is given by [13]

$\beta_{\mathrm{s}}=\frac{0.4}{\alpha_{1}-1}\left[\alpha_{1}-\frac{\varepsilon_{n}}{\varepsilon_{c r}}\right]+0.1$

where $\varepsilon_{n}$ is the strain normal to the crack direction. The variation of $\beta_{\mathrm{s}}$ with strain is shown in Fig. (3). At strain greater than $\alpha_{1} \varepsilon_{c r}$ a value of $\beta \mathrm{s}=0.1$ is used for numerical stability. 
Khalaf : Prediction Of Behaviour Of Reinforced Concrete Deep Beams With Web

\section{Steel Reinforcement}

The mechanical properties of steel are well-known and understood. Steel is homogeneous and has usually the same yield strength in tension and compression.

In the present study a bilinear elasto-plastic model with strain hardening is used for steel bars.

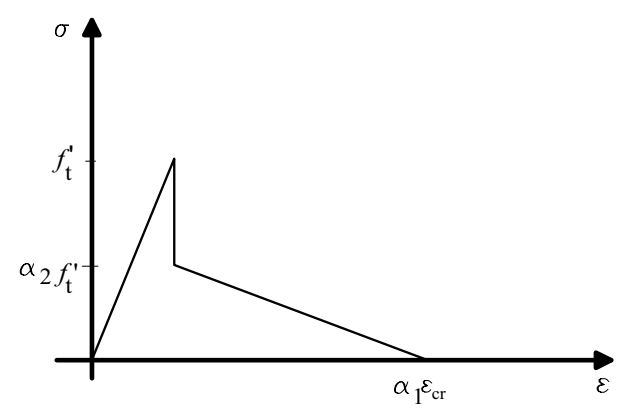

Fig. (2) Tension stiffening model

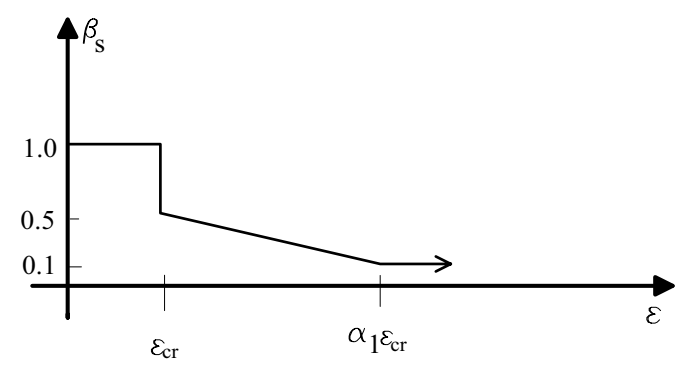

Fig.(3) Shear retention model

\section{Nonlinear Solution Technique}

The nonlinear analysis is based on the modified Newton-Raphson iterative procedure which is used to calculate stresses, strains and residual forces [8]. Every Gauss point is checked, at first, in order to determine whether loading or unloading takes place, and then in order to establish whether any crack closes or forms. Depending on the results of the previous checks, changes are introduced to the stressstrain matrices and consequently, to the stiffness matrix of the structure. Based on these modified matrices, displacement, strain and stress corrections are evaluated. In order to decide when the iteration should be terminated, a convergence criterion is required. In the present study, convergence is checked by the displacement convergence criterion.

\section{Applications}

Although there have been extensive tests on solid deep beams, there are only few published results on deep beams with web openings. Kong et al. [2] performed an extensive series of experiments on deep beams with web openings. Among the beams tested by Kong et al. [2] five beams have been chosen to examine the proposed finite element model. 


\begin{tabular}{llll} 
Al-Rafidain Engineering & Vol.15 & No.4 & 2007 \\
\hline
\end{tabular}

\section{Description of the Beams}

All beams, which are identical in geometry and longitudinal reinforcement, had a thickness of $100 \mathrm{~mm}$ and dimensions as shown in Fig. (4). The differences between these five beams were in the web reinforcement patterns (Fig. 5) and concrete properties (Table1). The longitudinal reinforcement consisted of one $20 \mathrm{~mm}$ diameter deformed bar of $430 \mathrm{~N} / \mathrm{mm}^{2}$ yield strength, anchored to external steel blocks at the ends. Web reinforcement consisted of $10 \mathrm{~mm}$ diameter deformed bar stirrups of $450 \mathrm{~N} / \mathrm{mm}^{2}$ yield strength.
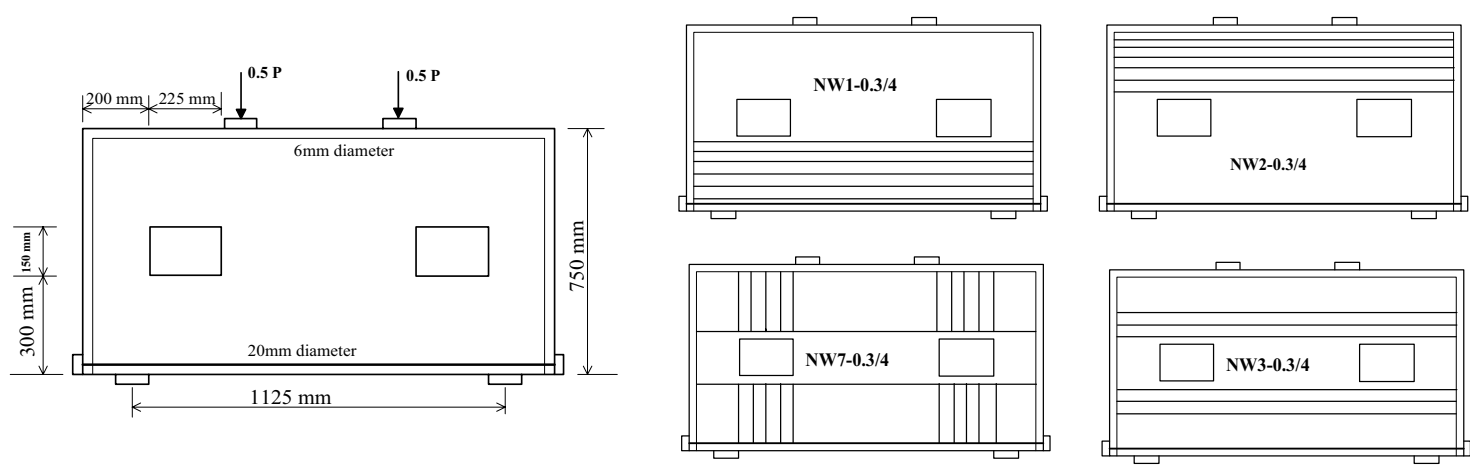

Fig. (4) Beam geometry

\section{Finite Element Representation}

Taking advantage of symmetry, only one half of the beam is considered. The finite element mesh typical of all beams investigated which consists of 68 elements, where the loading and supporting plates have been included in the mesh, boundary conditions, and loading used in the analysis are shown in Fig. (6). The position of bar elements is indicated by the dotted lines.

Fig. (5) Web reinforcement patterns

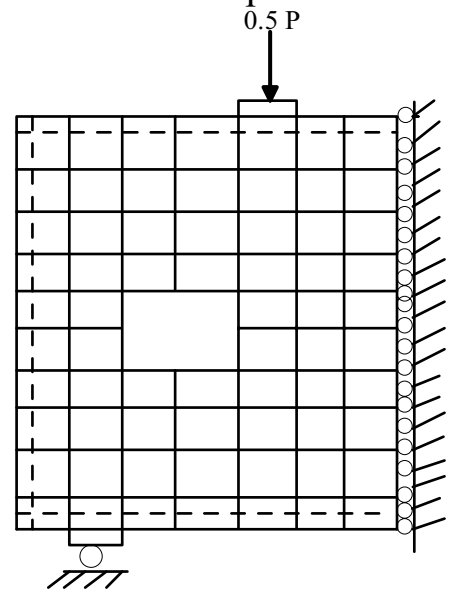

Fig.(6) The FE mesh 
Khalaf : Prediction Of Behaviour Of Reinforced Concrete Deep Beams With Web

\section{Discussion of the Results}

The predicted behaviour and the comparisons between the computed and experimental results are summarized below.

\section{Load-deflection relationships and deformed shapes}

The load-deflection experimental results are unavailable, thus the following discussion will be restricted to the computed load- deflection only. The analytical load-mid-span deflection relationships are shown in Fig. (7). It can be seen from these relationships that the presence of the web reinforcement and its arrangement has an influence on the beams response. The absence of web reinforcement in beam NO$0.3 / 4$ caused a reduction in load-carrying capacity and ductility where the failure is brittle and sudden. Improvements were significantly noted on response of the beams with different web reinforcement patterns. The best advantage could be gained by reinforcing the beam above and below the opening.
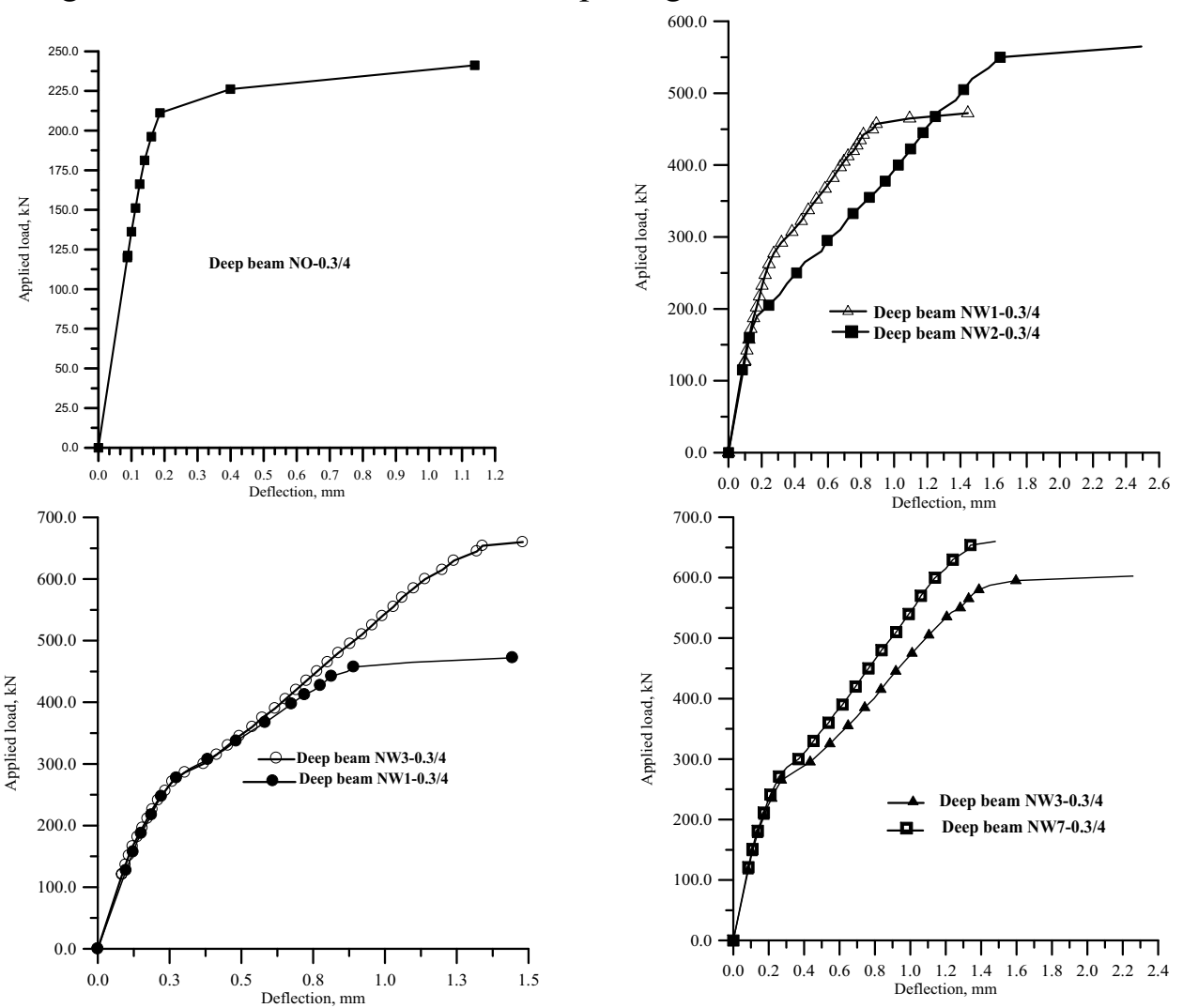

Fig.(7) Load-deflection relationships

Fig. (8) contains representations of the magnified deformed shapes of the beams at ultimate load. These shapes indicate that deformation occurs mainly by relative rotation of three distinct blocks of the beam: one above the opening, another below the opening and the third between the opening and the end of the beam [5]. 


\begin{tabular}{llll} 
Al-Rafidain Engineering & Vol.15 & No.4 & 2007 \\
\hline
\end{tabular}

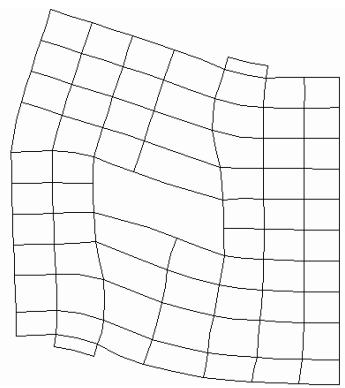

NO- $0.3 / 4$

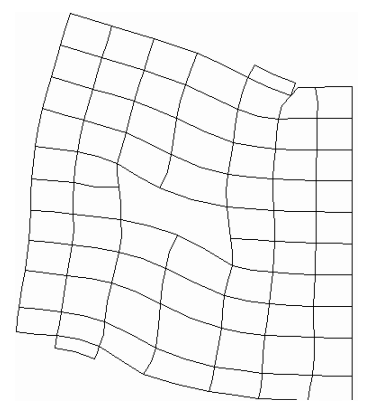

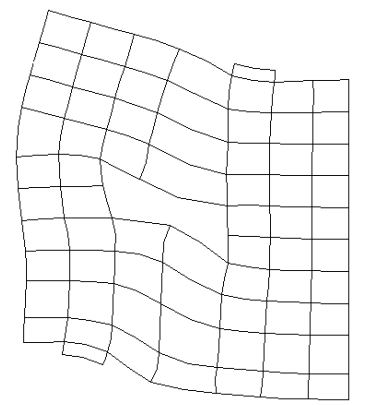

NW1-0.3/4

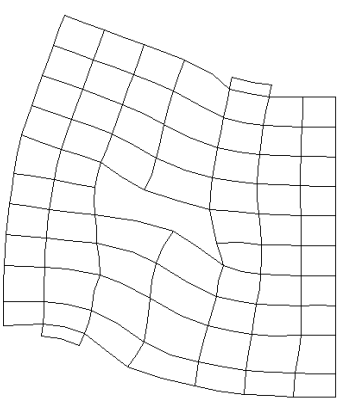

NW2-0.3/4

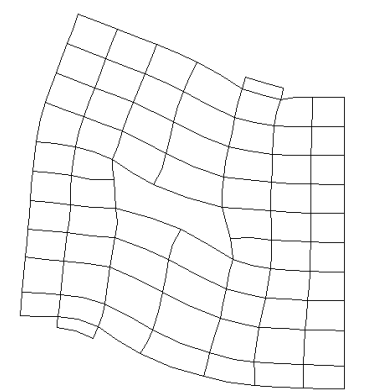

Fig. (8) Magnified deformed shapes

NW3-0.3/4

NW7-0.3/4

\section{Modes of failure and ultimate loads}

The general failure modes of reinforced concrete members are represented by the occurrence and development of cracks. The predicted and experimental cracking patterns of the beams at failure are shown in Fig. (9), and the occurrence of cracking is indicated by short lines, whereas crushed concrete is indicated by black spots. In all the beams, diagonal cracks appeared first at loads ranging from $118 \mathrm{kN}$ to $120 \mathrm{kN}$, being initiated at the bottom left corner of the opening. As the applied load was increased diagonal cracks were developed, approximately parallel to the original ones, and propagated both ways towards the support and loading point. Diagonal cracks are the obvious feature here as well as considerable damage around the opening and at point of application of loading. Note also the presence of horizontal cracking at the top left corner of the web opening. Flexural cracks (vertical cracks) also appeared in all beams. These cracks hardly penetrated the depth of the beams at mid-span.
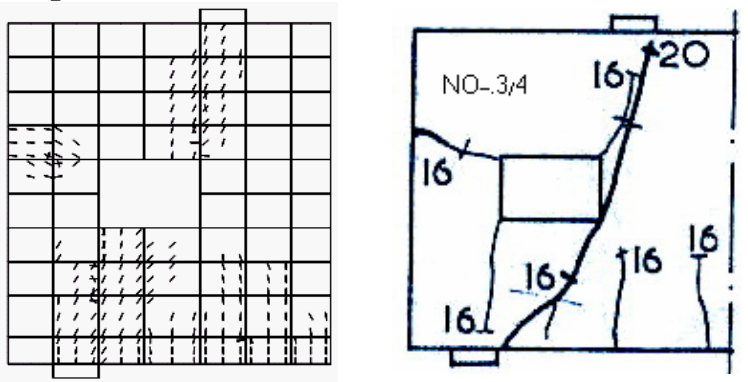

Fig. (9) The predicted and experimental crack patterns

$\mathrm{NO}-3 / 4$ 
Khalaf : Prediction Of Behaviour Of Reinforced Concrete Deep Beams With Web

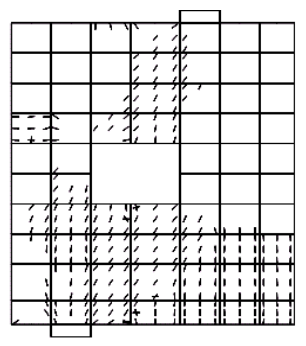

NW1

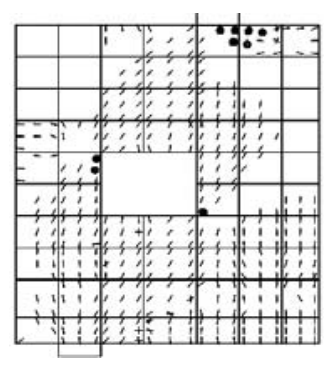

NW3
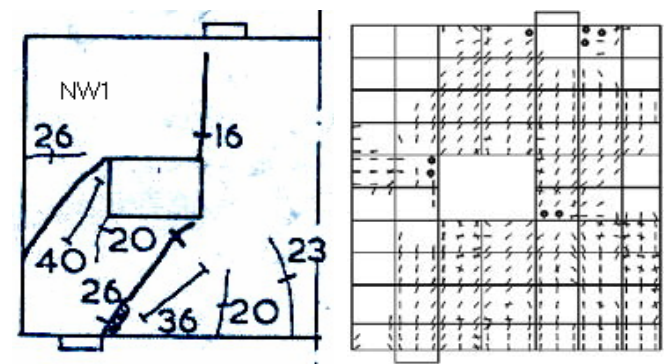

NW2
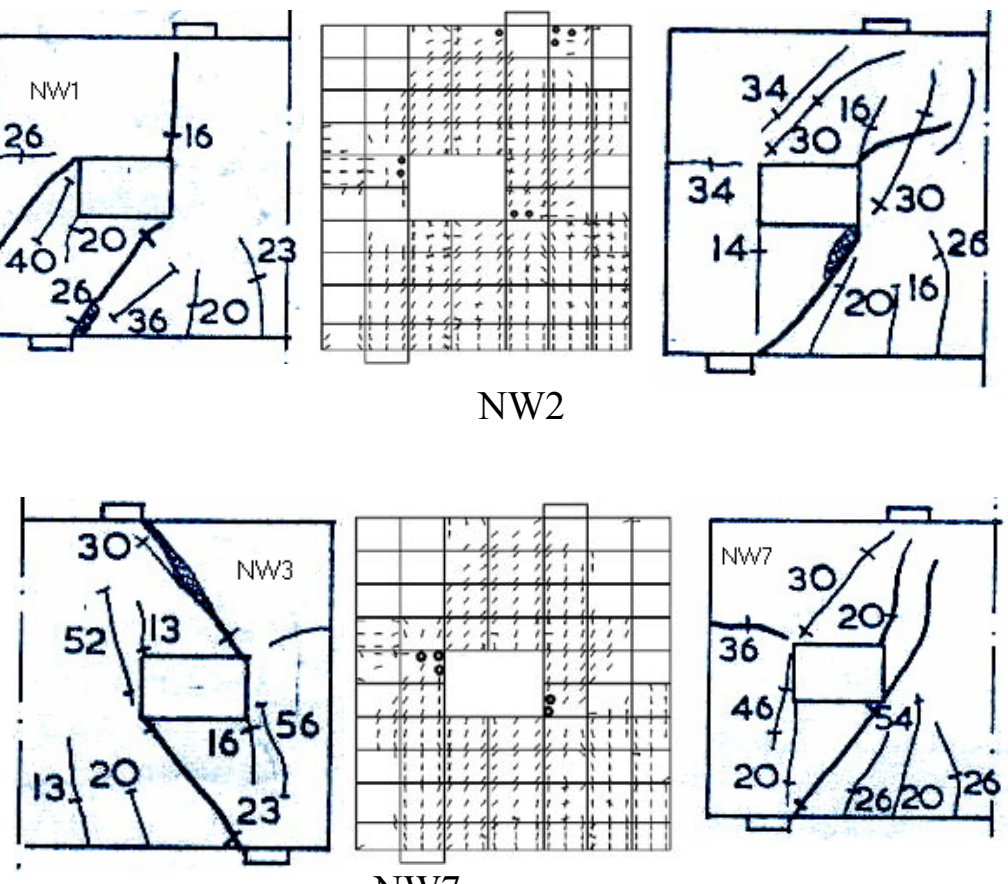

Fig.(9) continued

Table (2) shows the comparison between predicted and measured ultimate loads. It clearly demonstrates that a significant increase in the ultimate load of a beam with openings by use of web reinforcement, particularly if the reinforcement protects the regions above and below the opening. The comparison study in Table (2) shows that the present finite element model is more consistent than Kong's et. al estimates [2] and strut-and-tie approach [6]. It is also noticed that Kong's empirical equation cannot be used for beams NW1-0.3/4 and NW2-0.3/4.

Table (2): Ultimate loads comparisons

\begin{tabular}{|c|c|c|c|c|c|c|c|}
\hline \multirow{2}{*}{$\begin{array}{c}\text { Beam ref. } \\
\text { No. }\end{array}$} & \multirow{2}{*}{$\begin{array}{l}\text { Measured, } \\
P \\
\quad \mathrm{kN}\end{array}$} & \multicolumn{3}{|c|}{ Predicted, kN } & \multirow{2}{*}{$\frac{P_{1}}{P}$} & \multirow{2}{*}{$\frac{P_{2}}{P}$} & \multirow{2}{*}{$\frac{P_{3}}{P}$} \\
\hline & & $\begin{array}{ll}\text { Ref. (2), } \\
P_{1}\end{array}$ & $\begin{array}{l}\text { Ref.(6), } \\
P_{2}\end{array}$ & $\begin{array}{l}\text { Present, } \\
P_{3}\end{array}$ & & & \\
\hline NO.-0.3/4 & 240. & 367. & 316. & 241. & 1.53 & 1.32 & 1.0 \\
\hline NW1-0.3/4 & 420. & $* * *$ & 446. & 472. & $* * *$ & 1.06 & 1.12 \\
\hline NW2-0.3/4 & 580. & $* * *$ & 619. & 565. & $* * *$ & 1.07 & .97 \\
\hline NW3-0.3/4 & 620. & 651. & 643. & 660. & 1.05 & 1.04 & 1.06 \\
\hline NW7-0.3/4 & 720. & 591. & 771. & 618. & 0.82 & 1.07 & 0.86 \\
\hline
\end{tabular}

\section{Stresses distribution}

Although tests on beams provided useful recommendations on the strength of rein-forced concrete deep beams, the data so developed do not provide information in 
terms of a comprehensive stress distribution format in critical regions. However, finite elements technique provides a unified understanding of the pattern of stresses within the beam.

Typical stress distributions over the longitudinal section of the beam NO-0.3/4 are show in Fig. (10). From these diagrams it can been seen that a higher compressive stresses are concentrated at the upper left and lower right corners of the opening corners, support region, and the plate of loading. A high tensile strength concentration at the upper right and lower left corners of the opening and the bottom region of the beam. The paths joining the support and point of application of loading are subjected to the maximum shear stresses.

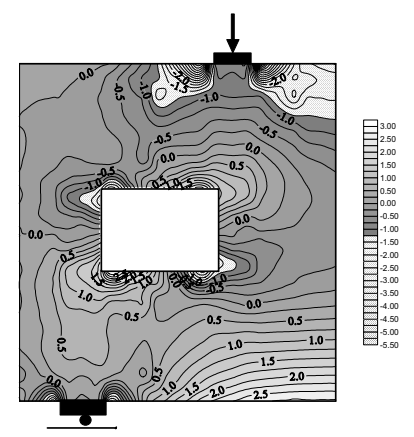

(a) stresses in $\mathrm{x}$-direction

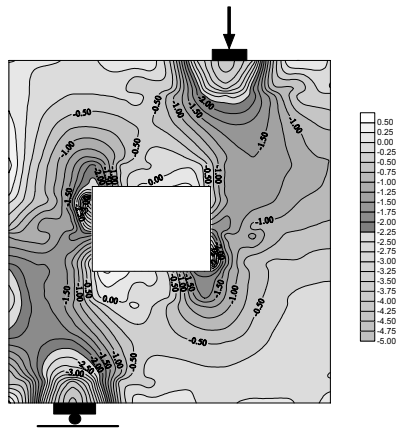

(b) stresses in y-direction

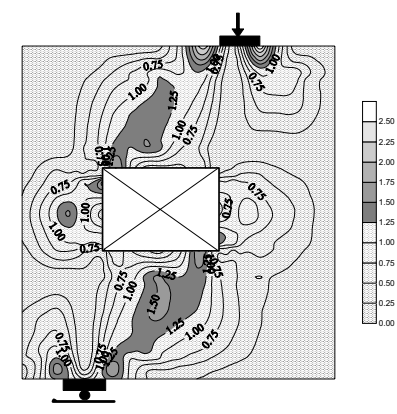

(c) shear stresses

Fig. (10)- stresses distribution for beam NO-0.3/4

Elastic bending stress at centerline of beam

NO-0.3/4 is shown in Fig. (11). It can be noted that the neutral axis does not lie at mid-depth and stress across any section exhibits nonlinear behaviour even at elastic range.

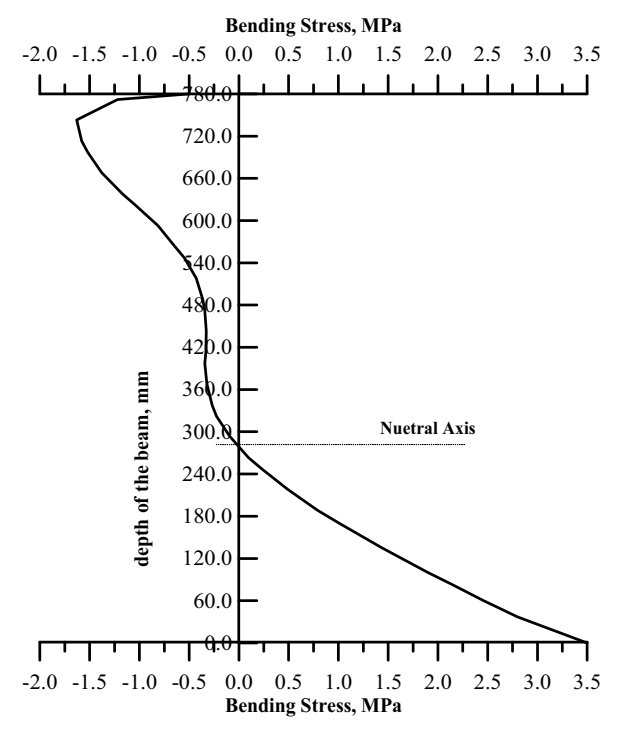

Fig.(11):Horizontal-Bending stress distribution for beam N0-0.3/4 
Khalaf : Prediction Of Behaviour Of Reinforced Concrete Deep Beams With Web

\section{Conclusions}

It is well recognized that the exact analysis of reinforced concrete deep beams is a complex problem; provision of openings in the web aggravates the situation and makes the beam highly indeterminate. However, such openings are often unavoidable because of the requirements of accessibility and of accommodating utility ducts. Up till now, no code pro-vision existed for design of such beams. Besides, there are very few published papers that include the analysis of deep beams with web openings and with web reinforcement. In the present study a nonlinear finite element model has been introduced.

The numerical method of analysis developed in the present study is capable of providing useful information about the responses of reinforced concrete deep beams with web openings under monotonic load conditions. When a good knowledge of the material properties of the beams is available, the behviour of the beams is predicted with reasonable accuracy.

\section{REFERENCES}

1.Sciammarella, C. A., "Effect of holes in deep beams with reinforced vertical edges", Engineering progress, University of Fla, 1963, 17, No. 12.

2. Kong, F. K., Sharp, G. R., Appleton, S. C., Beaumont, C. J. and Kubik, L. A., "Structural idealization for deep beams with web openings: further evidence", Magazine of Concrete Research, Vol. 30, No. 103, June 1978, pp. 89-95.

3. Ray, S. P. and Reddy, C. S., "Strength of reinforced concrete deep beams with and without opening in the web", The Indian Concrete Journal, Vol. 53, No. 9, September 1979, pp. 242-246.

4. Singh, R., Ray, S. P. and Reddy, C. S., "Some tests on reinforced concrete deep beams with and without opening in the web", The Indian Concrete Journal, Vol. 54, No. 7, July 1980, pp. 189-194.

5. Kubik, L. A., "Predicting the strength of reinforced concrete deep beams with web openings", Proceedings, Institution of Civil Engineers, London, Part 2, Vol. 69, December 1980, pp. 939-958.

6.Tan, K. H., Tong, K. and Tang, C. Y., "Consistent strut-and-tie modelling of deep beams with web openings", Magazine of Concrete Research, Vol. 55, No. 1, 2003, pp. 572-582.

7.Yang, K.H., Eun, H.C. and Chung, H.S., "The influence of web openings on the structural behavior of reinforced high-strength concrete deep beams", Engineering structures, in press, available on online www.sciencedirect.com

8.Zienkiewicz, O.C. and Taylor, R.L. "The Finite element method", ButterworthHeinemann, U.K., 2000.

9.Philips, D.V. and Zienkiewicz, "Finite element nonlinear analysis of concrete structures" Proceedings, Institution of Civil Engineers, London, Part 2, Vol. 61, March 1976, pp. 59-88. 
10. Kupfer, H., Hilsdrof, H. K. and Rusch, H., "Behaviour of concrete under biaxial stresses", Journal of American Concrete Institute, Vol. 66, No. 8, August 1969, pp. 6565-666.

11. Owen, D.R.J. and Figueiras, J.A., "Ultimate load analysis of reinforced concrete plates and shells, in Finite Element Software for Plates and Shells", E.Hinton and D.R.J.Owen (Eds.), Pineridge Press, U.K., 1984.

12. Al-Manasser, A.A. and Phillips, D.V., "Numerical study of some postcracking material parameters affecting nonlinear solutions in reinforced concrete deep beams", Canadian Journal of Civil Engineering, Vol. , No. 5, 7, pp.655-666.

13. Naji, H. H., "Nonlinear finite element analysis of reinforced concrete panels and infilled frames under monotonic and cyclic loading", Ph.D. thesis, University of Bradford, U.K., 1989. 